\title{
ROCHAS ORNAMENTAIS SILICÁTICAS DO ESTADO DE PERNAMBUCO
}

\author{
F. M. C. Oliveira ${ }^{1}$, T. M. F. Kálix ${ }^{1}$, M. L. S. C. Barros ${ }^{1}$, E. B. Melo ${ }^{1}$, P. O. B. Morais ${ }^{2}$ \\ ${ }^{1}$ Universidade Federal de Pernambuco e ${ }^{2}$ Universidade de Pernambuco \\ felisbela.oliveira@ufpe.br; thakalix@hotmail.com; mlbarros@ufpe.br; evenildodemelo@yahoo.com.br
}

Artigo submetido em junho/2013 e aceito em setembro/2013

\section{RESUMO}

As rochas ornamentais são materiais que agregam valor através de padrão cromático, desenho, textura e granulação. Segundo Mendes e Paiva (2002), Pernambuco está inserido na Província Borborema, de evolução marcada por grande mobilidade tectônica, com alternância de regimes compressivos e distensivos. Na região ocorreram 3 eventos tectônicos distintos, nos quais se registram jazidas de rochas não orientadas (granitoide) e movimentadas (ortognaisses e migmatitos). Dez litotipos foram catalogados: Red Brown, Samba Red, Salmão Lagoa, Rosa Imperial, Granito Frevo, rochas movimentadas, e Sunset Red, Vermelho Ventura, Vermelho Ipanema, Amarelo Ipanema, sendo o "Marrom Imperial" o que mais se destaca comercialmente, materiais isotrópicos. Os índices físicos de sete desses materiais se adéquam aos valores estabelecidos por Frazão \& Farjallat (1996), enquanto que as resistências à compressão de quatro rochas estão aquém desta mesma tabela. Apenas uma rocha apresenta resistência à flexão menor e outra baixa resistência ao pisoteio. As propriedades físicas e mecânicas das rochas de Pernambuco, comparadas àquelas propostas por Frazão \& Farjallat (1996), atestam materiais de boa qualidade podendo ser utilizadas em pisos de alta trafegabilidade; resistência mecânica podendo ser considerada elevada; as baixas absorção e porosidade indicam sua adequação a lugares úmidos observando, entretanto a composição mineralógica.

PALAVRAS-CHAVE: rochas ornamentais; índices físicos; resistências mecânicas; rochas de PE.

\section{SILICATIC DIMENSION STONES OF PERNAMBUCO STATE}

\begin{abstract}
Dimension stones are materials that add value through standard color, design, texture and grain. According to Mendes e Paiva (2002), Pernambuco is inserted in the Borborema Province of evolution marked by great tectonics mobility, alternating compressive and extensional regimes. In the region there were 3 distinct tectonic events, in which deposits of non-oriented rocks (granitoid) and moved rocks (orthogneisses and migmatites). Ten litho types were cataloged: Red Brown, Samba Red, Salmão Lagoa, Imperial Pink, Frevo Granite, moved rocks, and Sunset Red, Red Ventura, Red Ipanema, Yellow Ipanema, being the "Imperial Brown" the one that stands out most commercially, isotropic
\end{abstract}

materials. The physical indices of seven of these materials suited to values determined by Frazão \& Farjallat (1996), while the compressive strengths of four rocks are below this chart. Only one rock has lower flexural strength and other low resistance to trampling. The physical and mechanical properties of the rocks of Pernambuco, compared to those proposed by Frazão \& Farjallat (1996) attest good quality materials and can be used on surfaces with high trafficability; high mechanical strength; low absorption and porosity indicate their suitability for wet locations noting, however the mineralogical composition.

KEYWORDS: dimension stones; physical indices; mechanical strengths; rocks of PE. 


\section{ROCHAS ORNAMENTAIS SILICÁTICAS DO ESTADO DE PERNAMBUCO}

\section{INTRODUÇÃO}

\subsection{ROCHAS ORNAMENTAIS}

As rochas ornamentais e de revestimento, também chamadas pedras naturais, rochas lapídeas e rochas dimensionais, são materiais que agregam valor principalmente através de suas características estéticas, destacando-se o padrão cromático, desenho, textura e granulação. Os materiais naturais de ornamentação e revestimento abrangem as rochas que são extraídas em blocos ou placas, cortadas em formas variadas e têm suas faces beneficiadas através de esquadrejamento, polimento, lustro apicoamento e flamejamento. As principais rochas utilizadas incluem mármores, travertinos, granitos, ardósias, quartzitos, pedra sabão, etc. (CHIODI, 2001).

Os "granitos" correspondem cientificamente às rochas ígneas e metamórficas de granulometria grossa compostas principalmente de minerais félsicos. Enquanto os mármores resultam do metamorfismo de calcários e dolomitos. O padrão cromático é definido por minerais acessórios e impurezas. Quartzitos e arenitos são rochas compostas essencialmente por quartzo. Geralmente, arenitos são rochas sedimentares clásticas (originadas do acúmulo e consolidação de sedimentos de granulação areia: 0,02 a 2,0 mm), enquanto os quartzitos originam-se a partir de metamorfismo de rochas sedimentares. Conglomerados são também rochas sedimentares clásticas, (superior a 2,0 mm). Acham-se afetados por metamorfismo, o que thes confere maior coesão entre os grãos e maior resistência mecânica. As "ardósias" compõem-se essencialmente de mica (muscovita - sericita), quartzo e clorita. São de baixo valor comercial sendo tratadas como rochas semi ornamentais.

O uso e aplicação das rochas ornamentais e de revestimento baseiam-se no conhecimento de suas propriedades físicas e mecânicas, na sua composição mineralógica, textura, grau de microfissuramento e porosidade. Do mesmo modo, as informações sobre o ambiente no qual a rocha será aplicada influencia sobre a decisão da escolha da mesma: ambientes quentes e úmidos são naturalmente mais propícios para a alteração dos minerais constituintes da rocha; regiões de climas secos e quentes induzem a ciclos de dilatação/contração, o que finda por quebrar a rocha; locais de grande circulação de pessoas tais como saguões de aeroportos, centro de compras, supermercados requerem litotipos cujos constituintes mineralógicos apresentem dureza elevada. Frazão \& Farjallat (1996) indicam valores dos índices físicos e características mecânicas que devem ser observados para o melhor desempenho do material ornamental.

\subsection{ROCHAS ORNAMENTAIS SILICÁTICAS DO BRASIL}

A produção das rochas ornamentais apresentou crescimento acelerado nas últimas décadas, sendo estas utilizadas em ambientes externos de prédios, pisos, paredes, mesas e pias.

No país a produção nacional de mármores iniciou-se no sul do Estado de Minas Gerais, no município do Mar de Espanha, em 1908. Conseguindo cobrir 73\% do consumo nacional, em 1938. Até a primeira metade do Século $X X$, os mármores foram mais utilizados para usos ornamentais altamente decorativos, portanto, as lojas que trabalham com rochas ornamentais são denominadas, até o presente, "marmoraria". O uso dos "granitos" como material de acabamento decorativo iniciou-se na década de 1950, só sendo possível devido ao evento das serras 
diamantadas motorizadas. Antes este material era usado como soleiras, meio-fio de ruas e estradas, calçamentos, sem polimento de nenhuma natureza. (VARGAS, 2001).

Entretanto a expansão da produção e uso do granito ocorreu a partir do final da década de 80. O Brasil produz aproximadamente 1.200 variedades de rochas, 1.800 pedreiras ativas. Os principais estados produtores são Espírito Santo, Bahia, Ceará, São Paulo, Pernambuco, Goiás e Rio de Janeiro. O Brasil é um dos grandes produtores e exportadores mundiais de rochas ornamentais e de revestimento. A maior parte da produção é de rochas graníticas (60\%), 40\% compreendem mármores e outros materiais.

Grande parte dos "granitos" ornamentais do Brasil ocorre nas zonas de colisão continental. Estas foram formadas no final do Pré-Cambriano durante o evento da colagem continental, ou seja, agregação de pequenos continentes. Desta forma, a grande variedade de litotipos decorrentes destes eventos geológicos possuem atrativos de cor e textura tão admirados pelo mercado internacional. Rochas com tonalidades verdes, azuis, marrons, texturas movimentadas, grandes pórfiros, padrões considerados exóticos, agregam valor às rochas ornamentais brasileiras.

\section{ROCHAS ORNAMENTAIS SILICÁTICAS DE PERNAMBUCO}

\subsection{O SETOR DAS ROCHAS ORNAMENTAIS EM PERNAMBUCO}

Três estágios distintos podem ser identificados na evolução da indústria de Rochas Ornamentais de Pernambuco: O primeiro estágio corresponde à atuação pioneira da empresa União de Mármores e Granitos do Nordeste Ltda. que, na década de 1970, extraiu blocos aparelhados dos "granitos" Marrom Imperial e Cinza Pernambuco, chegando a colocar o material de tonalidade marrom nos mercados de Portugal e da Alemanha (MARANHÃO, 1991).

O segundo engloba a década de 1980 e teve uma sequência de eventos bem marcantes. Inicialmente, a realização, no quinquênio 1982-86, de um amplo programa de pesquisa, pioneiro no país, que cobriu todo o território estadual, conduzido pela empresa estatal estadual de mineração Minérios de Pernambuco S.A. Este levantamento, além de possibilitar a identificação de 220 diferentes tipos de granitos, 55 dos quais classificados como rochas ornamentais, ensejou a publicação, em 1987, do Catálogo de Granitos de Pernambuco - Rochas Para Revestimento.

O terceiro estágio abrange o início da década de 1990 quando ocorreu uma intensa mobilização do empresariado, capitaneada pela FIEPE - Federação das Indústrias do Estado de Pernambuco e pelo então Sindicato da Extração de Mármore, Calcários e Pedreiras e de Minerais Não Metálicos do Estado de Pernambuco, que possibilitou a instituição do Programa Pedra Bonita a partir do qual foram implantadas, nos Municípios de Bezerros e Belo Jardim, unidades industriais de beneficiamento de rochas.

Estimativas extraoficiais dão conta de que a produção mensal de blocos de rocha ornamental seria da ordem de $700 \mathrm{~m}^{3}$, dos quais cerca de $400 \mathrm{~m}^{3}$ destinados à exportação em forma bruta, principalmente para o mercado europeu. Cobertura de solo rasa ou inexistente, poucos problemas ecológicos sérios, abundância de mão- de- obra adaptável aos serviços de explotação, jazimentos em locais de fácil acesso e proximidade dos mercados europeus, asiático e norte-americano fazem de Pernambuco um produtor com grande potencialidade. As principais jazidas encontram-se na região do Agreste e Sertão.

\subsection{PRINCIPAIS LITOTIPOS SILICÁTICOS DE PERNAMBUCO}


Neste trabalho dez litotipos foram catalogados: "Red Brown", Samba "Red", Salmão Lagoa, Rosa Imperial, Granito Frevo, rochas movimentadas, e "Sunset Red", Vermelho Ventura, Vermelho Ipanema, Amarelo Ipanema, sendo o Marrom Imperial o que mais se destaca comercialmente, materiais isotrópicos. Dentre estes materiais, três tem ampla aceitação no mercado externo: Marrom Imperial, Samba "Red" e Rosa Imperial.

Segundo Mendes e Paiva (2002), geologicamente, Pernambuco está inserido na Província Borborema, cuja evolução é marcada por uma grande mobilidade tectônica, com alternância de regimes compressivos e distensivos. Na região ocorreram 3 eventos tectônicos distintos, relacionados ao Arqueano - Paleoproterozóico, Mesoproterozóico e Neoproterozóico, nos quais se registram abundantes ocorrências de rochas não orientadas (granitoide) e movimentadas (ortognaisses e migmatitos). Segundo Souza (2008), aproximadamente $70 \%$ do território pernambucano é formado por rochas do embasamento cristalino Pré-cambriano, que associado às características lito-estruturais do seu arcabouço geológico, reserva indiscutivelmente uma extraordinária potencialidade em granitos ornamentais.

\subsection{1. “GRANITO” MARROM IMPERIAL}

As principais ocorrências deste litotipo estão localizadas em Pedra do Navio e Fazenda das Pedras no município de Bom Jardim, a $110 \mathrm{~km}$ de Recife. Ocorrem sob a forma de lentes de monzonitos, pertencentes à Suíte Shoshonítica de idade Neoproterozóica. Petrograficamente apresenta textura granular isotrópica, constituída essencialmente por cristais de feldspatos regularmente distribuídos em uma matriz máfica homogênea, produzindo um padrão estético bastante atraente. Ademais, a coloração lilás dos cristais félsicos contrastando com a tonalidade esverdeada da matriz impingem um padrão de originalidade (SOUZA, 2008). Do ponto de vista petrográfico, o Marrom Imperial é um sienito. É uma rocha de granulação grossa, cor marrom escura, formada essencialmente por pórfiros de feldspatos marrons, circundados por auréolas finas de cores rosa, separadas por minerais máficos de cor preta a preta-esverdeada. Sua composição mineralógica é de $49 \%$ de ortoclásio, $25 \%$ de plagioclásio, $3 \%$ de augita, $12 \%$ de hornblenda, $5 \%$ de biotita e $6 \%$ de acessórios (figura 1). O Marrom Imperial possui reconhecida aceitação no mercado internacional ao preço de $\mathrm{U} \$ 700,00 / \mathrm{m}^{3}$. As características físicas e tecnológicas desta rocha estão listadas na Tabela 1.

A rocha encaixante deste litotipo, o quartzo - sienito também se presta ao setor de rochas ornamentais, constituindo material comum, comercializado no mercado interno sob o nome de Lilás Imperial. O método de lavra é em forma de bancadas, utilizando-se de fio diamantado, furação contínua, explosivos de baixa carga, "quarry-bar" (que são marteletes acoplados em colunas pneumáticas, que facilitam a operação de furação contínua) e "flame jet" (tipo de maçarico lança-chamas usado em lavra de rochas ornamentais) ocasionalmente (SOUZA, 2008). 


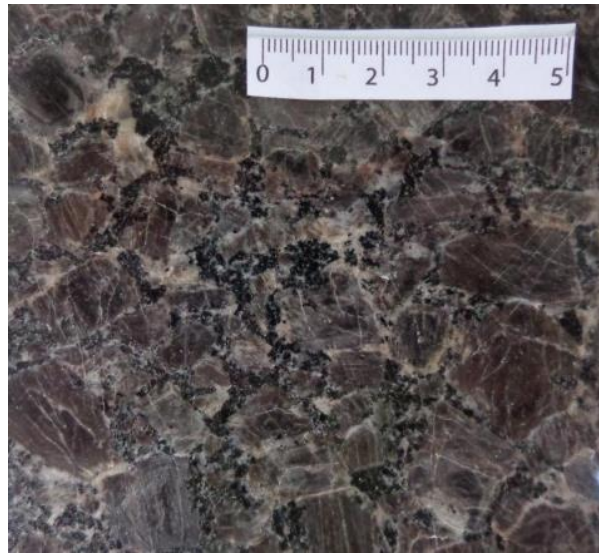

Figura 1- Aspecto da placa polida do "granito" Marrom Imperial. Autor: P. O. B. Morais.

\subsection{2. "GRANITO" “RED BROWN"}

Corresponde a um granitoide gnaissificado, ocorrendo na Serra Maniçoba, porção sul do Município de Sertânia a $272 \mathrm{~km}$ de Recife. Possui formato alongado na direção NE-SW da zona de cisalhamento de Cruzeiro do Nordeste, região do Moxotó, PE. A intrusão do corpo granítico ocorreu simultaneamente ao processo de cisalhamento, evidenciado pela enorme deformação do material, com consequente estiramento dos minerais (SOUZA, 2008). O método de lavra é realizado em bancadas altas com uso de fio diamantado, gerador e perfuratriz fundo-furo, não havendo utilização de perfuratrizes (figura 2).

Tabela 1: Características físicas e tecnológicas dos "granitos" Marrom Imperial, "Red Brown" e "Sunset Red".

\begin{tabular}{|l|c|c|c|}
\hline \multirow{2}{*}{ Características físicas e tecnológicas } & \multicolumn{3}{|c|}{ "Granitos" } \\
\cline { 2 - 4 } & Marrom Imperial* & "Red Brown" ** & "Sunset Red"** \\
\hline Massa específica seca $\left(\mathrm{kg} / \mathrm{m}^{3}\right)$ & 2.702 & 2.693 & 2.614 \\
\hline Massa específica saturada $\left(\mathrm{kg} / \mathrm{m}^{3}\right)$ & 2.718 & 2.712 & 2.622 \\
\hline Absorção d'água (\%) & 0,296 & 0,693 & 0,293 \\
\hline Porosidade (\%) & 0,796 & 1,862 & 0,765 \\
\hline Resistência à compressão simples (MPa) & 84,87 & 194,176 & 107,60 \\
\hline Resistência à tração por flexão (MPa) & 11,83 & 34,39 & 9,32 \\
\hline Resistência ao impacto de corpo duro (m) & $0,35 \mathrm{~m}$ & $\begin{array}{c}\text { moderada } \\
\text { resistência }\end{array}$ & $\begin{array}{c}\text { excelente } \\
\text { resistência }\end{array}$ \\
\hline Índice de desgaste Amsler a $500 \mathrm{~m}(\mathrm{~mm})$ & 0,39 & 0,317 & 0,283 \\
\hline Índice de desgaste Amsler a $1000 \mathrm{~m}(\mathrm{~mm})$ & 0,91 & 0,687 & 0,545 \\
\hline
\end{tabular}

Fonte: *KÁLIX, (2011). **SOUZA, (2008)

Apresenta bandamento levemente ondulado, dando aspecto de movimentação das bandas o que é bastante apreciado pelo mercado de rochas ornamentais. A tonalidade de rocha é bastante variada incluindo tons amarronzados, esverdeados e róseos. A matriz é constituída por minerais fortemente estirados e com alguma silicificação difusa. Segundo Mendes (2008), é constituída por $50 \%$ de matriz milonítica, $18 \%$ de anfibólio, 15\% de plagioclásio, $15 \%$ de quartzo e $2 \%$ de acessórios, estes representados por opacos, titanita, alanita, calcita. Na Tabela 1 são listadas as características físicas e tecnológicas deste material. 


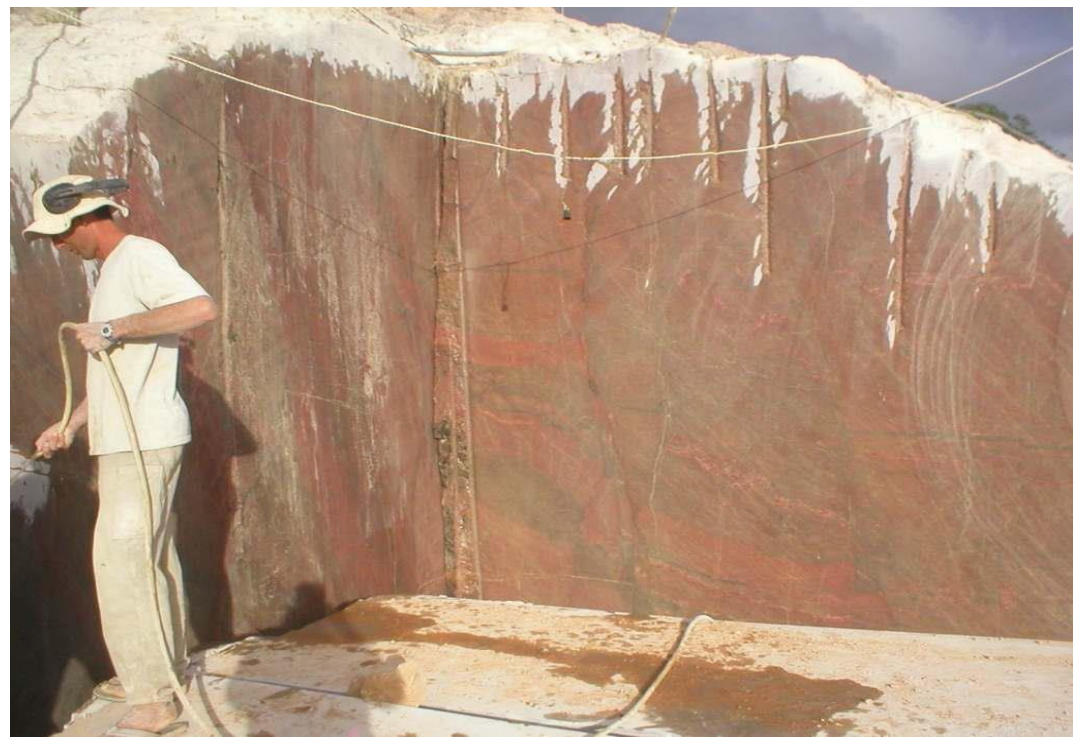

Figura 2: Detalhe da frente de explotação, em maciço elevado, do “granito" “Red Brown”. Fonte: Araújo et al. (2007).

\subsection{3. "GRANITO" “SUNSET RED”}

Ocorre em Bacoré, localidade do município de Arcoverde, a $263 \mathrm{~km}$ de Recife. A rocha apresenta textura grosseira e coloração de rosa - escura a vermelha com fenocristais de $\mathrm{K}$ feldspato alcançando até $2,0 \mathrm{~cm}$. Os cristais de quartzo se encontram disseminados de forma aleatória. Segundo Mendes (2008), é constituído por $70 \% \mathrm{~K}$-feldspato (microclina), 20\% de quartzo, $10 \%$ de plagioclásio e menos de $1 \%$ de acessórios, principalmente por clorita, muscovita, opacos e biotitas (figura 3). Trata-se de um álcali-feldspato granito a sienogranito porfirítico.

Os tipos de contato dessa unidade com os migmatitos encaixantes são gradativos e difusos, ocorrendo por vezes, contatos bruscos por falhamentos. Esta unidade constitui imensas concentrações sob a forma de grandes maciços rochosos (MENDES, 2008).

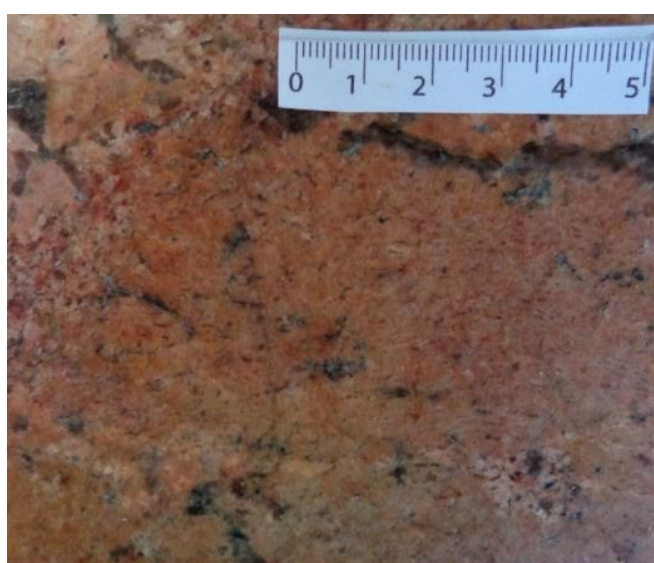

Figura 3: aspecto da placa polida do "granito" "Sunset Red". Autor: P.O.B. Morais

Visando a produção de blocos com custos compatíveis e em função da morfologia e dos parâmetros geológicos levantados no maciço rochoso de Bacoré, definiu-se tecnicamente o método de lavra a ser adotado por bancadas altas.

A lavra é desenvolvida com cortes programados, utilizando o fio diamantado, desmonte de pranchas, e emprego de argamassa expansiva. 
Toda a produção é exportada para a Itália, através da empresa "Red Granite", que o comercializa no mercado europeu com o nome de "Sunset Red" ao preço de US\$600,00/m ${ }^{3}$. Na Tabela 1 são listados os valores obtidos a partir de ensaios tecnológicos.

\subsection{4. “GRANITO” SAMBA “RED”}

Este granitoide ocorre extensivamente sob a forma de maciços rochosos entre as cidades de Venturosa, Pedra e Garanhuns, constituindo faixa de aproximadamente $1.000 \mathrm{Km}^{2}$ de área de afloramento. Está inserido no Complexo Belém do São Francisco. Trata-se de um migmatito contendo faixas cor de rosa, intercaladas com faixas de cor cinza e/ou preta, que se encontram retorcidas apresentando ainda mudança de tonalidades e de padrões estrutural e textural. A faixa de cor rosa tem geralmente entre 0,2 e 5,0 cm de espessura, formada essencialmente por microclina, plagioclásio e quartzo, sendo que a microclina é o mineral mais abundante, seguido do plagioclásio. A faixa de cor cinza tem entre 0,2 e 3,0 cm de espessura e mostra isoladamente um aspecto gnáissico, sendo formada por finos leitos de biotita, intercalados com leitos de quartzo/feldspato. Nestes, a biotita é o mineral mais abundante (figura 4).

A mineração ATT - Mineração Ltda., desenvolve a lavra deste litotipo, na Fazenda Jucá, município de Pedra, através de bancadas altas e uso de fio diamantado, gerador e perfuratriz fundo-furo, marteletes e massa expansiva. O preço bruto do "granito" Samba "Red" é de R\$ $300,00 / \mathrm{m}^{3}$. Na Tabela 2 estão colocadas as características físicas e tecnológicas desta rocha.

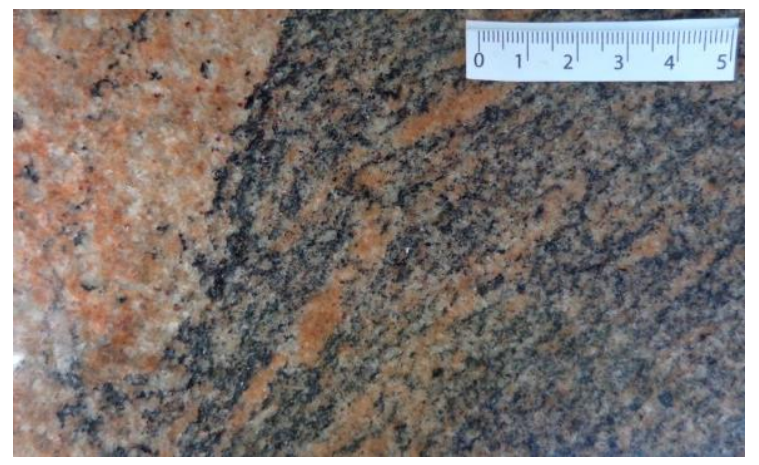

Figura 4: "Granito" Samba "Red" mostrando o padrão original de cor e de fluxo de movimento, além do ótimo lustro em chapa polida. Destaque para os mega cristais róseo-avermelhado de feldspato que se harmonizam em um padrão bastante movimentado. Autor: P.O.B. Morais.

\subsubsection{GRANITOS VERMELHO VENTURA, AMARELO IPANEMA E VERMELHO IPANEMA}

Estão localizados na Fazenda Peri-Peri (Venturosa) e Fazenda Laje (Pedra), distando respectivamente $245 \mathrm{~km}$ e $267 \mathrm{~km}$ do Recife. Aparece associados à biotita-anfibólio granitoide grosseiro, com textura porfirítica de cor avermelhada (Vermelho Ventura) (figura 5) e fácies equigranular média de coloração amarelo e avermelhada (Amarelo/Vermelho Ipanema). Segundo Mendes e Paiva (2002), estes litotipos estão inseridos na Suíte potássica-calcialcalina do Neoproterozóico.

A jazida do granito Vermelho Ventura, na Fazenda Peri-Peri, município de Venturosa é constituída por grandes matacões, dispondo de reservas consideráveis nas encostas dos morros, os quais são puxados por gravidade por meio de guinchos até a praça principal, onde se encontra o pau de carga. O desmonte é feito através de um furo central raiado segundo o as direções preferenciais de partição da rocha ("rift") da rocha, aplicando-se detonação com pólvora negra e 
cordel. Em seguida, o desdobramento dos blocos é realizado com auxílio de marteletes manuais, cunhas e pixotes.

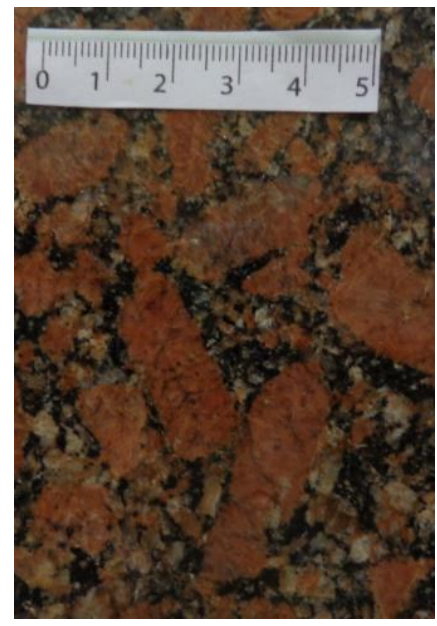

Figura 5: Placa dos granito Vermelho Ventura. Os pórfiros vermelhos são de microclina e as concentrações escuras são de máficos, especialmente a biotita. Autor: P.O.B. Morais.

A lavra do Granito Amarelo Ipanema ocorre na localidade da Serra do Caboclo, município de Pedra. Trata-se de uma rocha de cor clara com tonalidade dominante róseo-pálida a levemente amarelada com pontuações pretas. Entre os minerais destacam-se feldspatos esbranquiçados, róseos pálidos, quartzo e pontuações de biotita. A ocorrência de defeitos (trincas, veios e xenólitos) é pouco comum e os matacões mostram-se boa uniformidade cromática e textural. Na Tabela 2, abaixo, são listados os ensaios tecnológicos dos Granitos Vermelho Ventura, Vermelho Ipanema e Amarelo Ipanema.

Tabela 2: Características físicas e tecnológicas dos granitos Samba “Red”, Vermelho Ventura, Amarelo Ipanema e Vermelho Ipanema.

\begin{tabular}{|l|c|c|c|c|}
\hline \multirow{2}{*}{ Características físicas e tecnológicas } & \multicolumn{4}{|c|}{ “Granitos" } \\
\cline { 2 - 5 } & Samba Red* & $\begin{array}{c}\text { Vermelho } \\
\text { Ventura* }\end{array}$ & $\begin{array}{c}\text { Vermelho } \\
\text { Ipanema** }\end{array}$ & $\begin{array}{c}\text { Amarelo } \\
\text { Ipanema* }\end{array}$ \\
\hline Massa específica seca $\left(\mathrm{kg} / \mathrm{m}^{3}\right)$ & ------------ & --------- & --------- & 2.623 \\
\hline Massa específica saturada $\left(\mathrm{kg} / \mathrm{m}^{3}\right.$ ) & 2.650 & 2.670 & 2.650 & 2.634 \\
\hline Absorção d' água (\%) & 0,34 & 0,34 & 0,46 & 0,358 \\
\hline Porosidade (\%) & & 0,95 & 1,24 & 0,944 \\
\hline $\begin{array}{l}\text { Resistência à compressão simples } \\
\text { (MPa) }\end{array}$ & 96,6 & 95,12 & 143,18 & 105,42 \\
\hline Resistência à tração por flexão (MPa) & ---------- & ----------- & 17,45 & 14,11 \\
\hline $\begin{array}{l}\text { Índice de desgaste Amsler a 500 m } \\
\text { (mm) }\end{array}$ & -------- & --------- & ------- & 0,447 \\
\hline $\begin{array}{l}\text { Índice de desgaste Amsler a } 1000 \mathrm{~m} \\
\text { (mm) }\end{array}$ & ---------- & ----------- & ----------- & 1,60 \\
\hline
\end{tabular}

Fonte: *SOUZA (2008). **MARANHÃO (1991).

\subsection{6. "GRANITO” SALMÃO LAGOA E “GRANITO” ROSA IMPERIAL}

Este litotipo, Salmão Lagoa, representa o migmatito do Complexo Belém do São Francisco, de idade mesoproterozóica. Os migmatitos se apresentam bastante movimentados com cores 
rosadas a avermelhadas e padrão estrutural com boa aceitação do ponto de vista estético (SOUZA, 2008).

A Mineração Coto Comércio Importação Exportação Ltda., desenvolve, no granitoide Salmão Lagoa, município de Alagoinha, a $223 \mathrm{~km}$ de Recife, lavra em forma de bancadas com 5 a $7 \mathrm{~m}$ de altura, utilizando-se de "flame jet" e fio diamantado. A furação é feita com auxílio de perfuratriz tipo "quarry-bar" e explosivos. O preço no mercado externo é de $\mathrm{R} \$ 1.280,00 / \mathrm{m}^{3}$.

O "granito" Rosa Imperial ocorre na Fazenda Aline no município de Garanhuns, a 230 km de Recife. Representa um migmatito movimentado, pertencente ao Complexo Belém do São Francisco. Exibe neossoma de cor rosa suave a avermelhada, ricos em feldspato potássico, associado à zona de cisalhamento dúctil e a corpos máficos pré-existentes, de composição anfibolítica. Na localidade ocorrem dois fácies de migmatitos: um tipo com coloração cinza-clara devida aos cristais de feldspatos inclusos em matriz de granulação média, e outro, também com matriz de granulometria, com coloração róseo-avermelhada por conta dos cristais de feldspatos potássicos, ausência de hornblenda e acréscimos consideráveis na quantidade de biotita, sendo esta última unidade de maior interesse por parte dos consumidores, denominada comercialmente de "granito" Rosa Imperial. É uma rocha com padrão movimentado já consagrado no mercado internacional (figura 6).

Segundo Carmona (2002), nos resultados dos ensaios de determinação de alterabilidade química do migmatito "Rosa Imperial", apesar da agressividade a que foi submetido este material, por diversos agentes químicos mais comuns de serem encontrados em lares e escritórios (sais, graxas, sabões, detergentes, óleos minerais e vegetais, ácidos e bases), não apresenta restrições sensíveis ao uso em locais sujeitos aos agentes intempéricos externos e em ambientes internos tais como balcões de cozinhas, banheiros, etc. Este fato provavelmente se deve à sua composição mineralógica rica em feldspatos potássicos e pobre em minerais ferro magnesianos e ainda à sua granulometria média, portanto menor superfície específica.

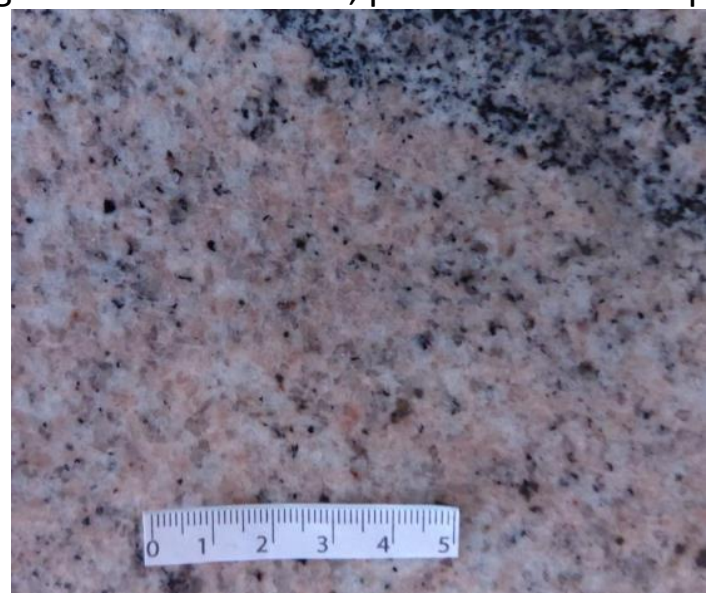

Figura 6: Placa polida do "granito" Rosa Imperial apresentando coloração rósea, resultante da presença de cristais de feldspato alcalino. Autor: P.O.B. Morais.

$\mathrm{Na}$ Tabela 3 estão mostrados resultados dos ensaios das características físicas e mecânicas dos "granitos" Rosa Imperial e Salmão Lagoa. 
Tabela 3: Características físicas e tecnológicas dos "granitos" Salmão Lagoa, Rosa Imperial e Frevo.

\begin{tabular}{|l|c|c|c|}
\hline \multirow{2}{*}{ Características físicas e tecnológicas } & \multicolumn{3}{|c|}{ Granitos } \\
\cline { 2 - 4 } & Salmão Lagoa* & Rosa Imperial** & Frevo* \\
\hline Massa específica seca $\left(\mathrm{kg} / \mathrm{m}^{3}\right)$ & 2.692 & 2.610 & 2.660 \\
\hline Massa específica saturada $\left(\mathrm{kg} / \mathrm{m}^{3}\right)$ & 2.704 & 2.616 & 2.670 \\
\hline Absorção d' água (\%) & 0,470 & 0,258 & 0,26 \\
\hline Porosidade (\%) & 1,265 & 0,676 & 0,65 \\
\hline Resistência à compressão simples (MPa) & 77,85 & 148,15 & 149,50 \\
\hline Resistência à tração por flexão (MPa) & 17,25 & 15,93 & 17,67 \\
\hline Índice de desgaste Amsler a 500 m (mm) & 0,05 & 0,33 & 0,35 \\
\hline $\begin{array}{l}\text { Índice de desgaste Amsler a } 1000 \mathrm{~m} \\
\text { (mm) }\end{array}$ & 0,190 & 0,65 & 0,64 \\
\hline
\end{tabular}

Fonte: *SOUZA (2008); ROLIM FILHO (1996).

\subsection{8. "GRANITO" FREVO}

Este litotipo está inserido no Complexo Sertânia do Mesoproterozóico e constitui um paragnaisse granadífero a biotita, intensamente migmatizado, de coloração róseo-avermelhada, rico em feldspato potássico e paleossoma de quartzo, biotita e granada (figura 7). Em termos estruturais apresenta-se intensamente dobrado e afetado por uma intensa tectônica tangencial que atuou na região.

O aspecto multicolorido, foliado e dobrado deste migmatito, resulta da existência de neossoma bastante deformado e rico em feldspato potássico, responsáveis pela coloração rosa avermelhada do litotipo.

No mercado externo os blocos brutos, são negociados na faixa de US\$ $500,00 / \mathrm{m}^{3}$. Os ensaios dos índices físicos e tecnológicos do Granito Frevo são listados na Tabela 3 acima.

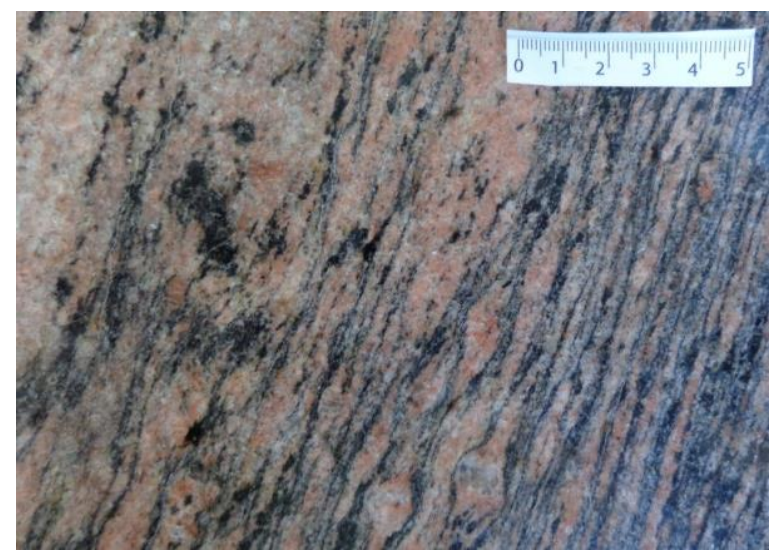

Figura 7: Placa polida do “granito" Frevo - Sítio Jaú, Sertânia, PE. Autor: P.O.B. Morais.

\section{DISCUSSÕES}

A utilização das rochas ornamentais pressupõe o conhecimento das características intrínsecas do material assim como as do meio, onde estas serão aplicadas. Desta forma a escolha adequada do litotipo é função da composição mineralógica, textura, porosidade e densidade da rocha e também de suas propriedades mecânicas.

Os principais ensaios adotados no Brasil para a qualificação das rochas ornamentais direcionados ao mercado interno ou externo são: petrografia, índices físicos (densidade aparente, porosidade aparente, e absorção d'água), dilatação térmica linear, desgaste abrasivo, 
impacto de corpo duro, resistência à flexão (módulo de ruptura), resistência à compressão uniaxial, congelamento e degelo conjugado à compressão. Estes ensaios encontram-se normalizados pela ABNT - Associação Brasileira de Normas Técnicas - através das Normas 15845 e 12042. A especificação dos valores limites para nortear os usos do material pétreo de revestimento são definidos pela norma 15844, que tomaram como referência os valores limites propostos por Frazão \& Farjallat (1996), apresentados na Tabela 4.

Tabela 4: valores sugeridos por Frazão \& Farjallat (1996)

\begin{tabular}{|l|c|}
\hline \multicolumn{1}{|c|}{ Propriedades } & Valores sugeridos por Frazão \& Farjallat \\
\hline Densidade $\left(\mathrm{kg} / \mathrm{m}^{3}\right)$ & 2.550 \\
\hline Porosidade aparente (\%) & $<1,0$ \\
\hline Absorção aparente $(\%)$ & $<0,4$ \\
\hline Velocidade de Propagação de Ondas $(\mathrm{m} / \mathrm{s})$ & 4000 \\
\hline Dilatação Térmica Linear $\left(10^{3} / \mathrm{mm}^{\circ} \mathrm{C}\right)$ & 12,0 \\
\hline Desgaste Amsler $(\mathrm{mm})$ & 1,0 \\
\hline Compressão Uniaxial (MPa) & 100,0 \\
\hline Flexão (módulo de ruptura) $(\mathrm{MPa})$ & 10,0 \\
\hline Módulo de deformabilidade estático & 30,0 \\
\hline Impacto de corpo duro (m) & 0,40 \\
\hline
\end{tabular}

Comparando os valores observados nas tabelas 1, 2 e 3 com aqueles propostos por Frazão \& Farjallat (1996), constantes na Tabela 4, e considerando-se a composição mineralógica da rocha, indica-se a seguir as possíveis aplicações para os dez litotipos considerados neste trabalho. De acordo com a Tabela 1, conclui-se que o "granito" Marrom Imperial é pouco resistente à compressão, apresenta valor razoável para a resistência à tração, absorve pouca água. Pode, pois, ser utilizado em pisos onde haja pouca circulação de pessoas (alto valor para o desgaste Amsler), revestimento de paredes internas, mobílias. Não recomendável em locais onde se utilizam muitos agentes químicos, produtos de limpeza, como cozinha, banheiros e áreas externas, devido à sua composição mineralógica de elevado teor de plagioclásio. Indicado como revestimento interno para áreas secas.

Em relação ao "granito" "Red Brown", este é indicado como revestimento em ambientes internos, como áreas íntimas, área social e mobília. Oferece uma moderada resistência ao impacto, fator desejável em ambientes com intensa trafegabilidade. Não recomendada a sua aplicação em áreas úmidas como, banheiros e cozinhas, uma vez que apresenta um elevado índice de absorção d'água, pois sua composição mineralógica (matriz milonítica, anfibólio, plagioclásio, quartzo e acessórios representados por opacos, titanita, alanita, calcita) favorece a alterabilidade do mesmo. O "granito" "Sunset Red" apresenta baixo índice de absorção d'água, excelente resistência ao impacto de corpo duro; os resultados do desgaste Amsler indicaram uma dureza mediana a elevada, aplicável em locais de tráfego moderado. Pode ser utilizado, porém, com algumas restrições, para aplicação em pavimentação tanto interna como externa. Quanto ao Samba "Red" é indicado para uso em ambientes internos e externos, uma vez que seu índice de absorção d'água é baixo, resistente a choque térmico, podendo ser utilizado em locais onde ocorrem oscilações de temperatura, como áreas externas.

Quanto ao granito Vermelho Ventura, em função de suas características tecnológicas, pode ser aplicado como revestimento interno e externo, fachadas, mobílias, pisos, paredes, etc. Apresenta baixo índice de absorção d'água, o que dificulta o processo de alteração apesar de ser constituído por minerais suscetíveis a alterações. O granito Vermelho Ipanema apresenta valores de absorção d'água acima do recomendado, é uma rocha resistente à compressão, à flexão, 
resistente às mudanças de temperatura. Pode ser aplicada em ambientes internos, em pisos, paredes, nas áreas sociais. Não se recomenda aplicá-la em cozinhas e em ambientes externos, devido à mesma apresentar um índice moderado em absorção d'água, para isso, deve-se levar em consideração o clima de região. O granito Amarelo Ipanema está dentro do limite de absorção d'água, porosidade moderada, boa resistência à compressão e também boa resistência à tração. Pode ser aplicada em ambientes internos, onde não haja umidade excessiva, a fim de evitar alterações mineralógicas. Pode ser aplicado também onde haja constante circulação de pessoas, como área social. Indicada como revestimento em áreas íntimas, mobílias, paredes.

O "granito" Salmão Lagoa apresenta uma porcentagem moderada de absorção d'água, consequentemente sua porosidade é mais elevada, baixa resistência à compressão. Indicada como revestimento em ambientes internos, aonde haja moderada circulação de pessoas, pode ser aplicada nas áreas íntimas, social, mobílias, rodapés. Evitar áreas úmidas como banheiros, cozinhas e áreas externas. Quanto ao "granito" Rosa Imperial, ele absorve pouca água, consequentemente é pouco poroso, apresenta considerável resistência à compressão e à tração. Sua aplicação é indicada em ambientes internos e externos, como pisos, paredes, fachadas, mobílias, etc. O "granito" Frevo tem baixa porosidade e absorção, tem excelente resistência à compressão e tração. É indicado como revestimento de ambientes internos e externos em pisos, paredes, mobílias, fachadas, etc. Apresenta características estético-decorativas, tipo mosaico, etc.

\section{CONCLUSÕES}

As aplicações das rochas ornamentais obedecem, via de regra, ao trinômio: estéticadurabilidade-custo. Entretanto a vertente mais privilegiada pelos arquitetos é a beleza. As características intrínsecas da rocha (composição mineralógica, porosidade, resistências) assim como do meio onde o material pétreo de revestimento será aplicado (fatores como temperatura, quantidade de água, $\mathrm{pH}$ do meio e potencial de oxi-redução) exercem fundamental importância na durabilidade do revestimento. Isto posto, considerando-se as rochas ornamentais de Pernambuco, os padrões estéticos são bastante atraentes para o mercado: materiais homogêneos (Marrom Imperial, Vermelho Ventura, Amarelo Ipanema, Vermelho Ipanema, "Sunset Red") e movimentados (Rosa Imperial, "Red Brown", Samba "Red", Salmão Lagoa e Frevo), com cores variando do marrom escuro ao rosa. Quanto aos parâmetros físicos (densidade, porosidade e absorção) e mecânicos (desgaste, compressão, flexão e impacto), apenas três dos materiais pétreos pernambucanos em epígrafe apresentam características compatíveis com aquelas propostas por Frazão \& Farjallat. Estes materiais, o Rosa Imperial, Frevo e Vermelho Ipanema, podem ser usados sem restrição, em revestimentos externos, internos, áreas secas e/ou molhadas. Com relação à aplicação dos outros litotipos, seus usos devem estar condicionados à observação do parâmetro que não obedece à Tabela 4 (Frazão \& Farjallat). Materiais de porosidade e absorção elevadas ("Red Brown" e Salmão Lagoa) não podem revestir áreas externas e/ou úmidas. Enfim, as propriedades físicas e mecânicas das rochas de Pernambuco, comparadas àquelas propostas por Frazão \& Farjallat (1996), atestam materiais de boa qualidade: podem ser utilizados em pisos de alta trafegabilidade; as resistências mecânicas podem ser consideradas elevadas; as baixas absorção e porosidade da maior parte dos materiais indicam sua adequação a lugares úmidos. Entretanto a composição mineralógica deve ser observada, pois a durabilidade da rocha depende da composição mineralógica e do meio em que está ficará inserida. 


\section{REFERÊNCIAS BIBLIOGRÁFICAS}

ASSOCIAÇÃO BRASILEIRA DE NORMAS TÉCNICAS - ABNT (NBR 15844). Rochas para revestimento - Requisitos para granitos. 2p. 2010.

ASSOCIAÇÃO BRASILEIRA DE NORMAS TÉCNICAS - ABNT (NBR 15845). Rochas para revestimento - Métodos de ensaio. 32p. 2010.

ASSOCIAÇÃO BRASILEIRA DE NORMAS TÉCNICAS - ABNT (NBR 12042). Materiais inorgânicos Determinação do desgaste por abrasão. 1992.

ARAÚJO, V.: SOUZA, J. C.; ROLIM, J. L. F. Diagnóstico do setor de rochas ornamentais e de revestimento do Estado de Pernambuco. In: XXII Simpósio de Geologia do Nordeste; III Congresso Brasileiro de Rochas Ornamentais; VI Simpósio de Rochas Ornamentais do Nordeste, 2007, Natal. Resumos. Natal: SBG Núcleo Norte Nordeste, 2007. CD-ROOM (Boletim Núcleo Norte Nordeste da SBG, 20).

CARMONA, L. C. M. C. Geologia, Geoquímica E Avaliação Econômica Do Migmatito Rosa Imperial., Domínio Meridional Da Província Borborema, Nordeste Brasileiro, Dissertação de Mestrado, Programa de Pós-Graduação em Geociências, UFPE, 2002. 202p.

CHIODI FILHO, C. - Situação e Perspectivas Brasileiras no Setor de Rochas Ornamentais e de Revestimento. In: Simpósio Brasileiro de Rochas Ornamentais; Seminário de Rochas Ornamentais do Nordeste, 2001. Salvador. Anais. Rio de Janeiro: CETEM; SGM, 2001. CD-ROM.

FRAZÃO, E. B.; FARJALLAT, J. E. S. Proposta de especificação para rochas silicáticas de revestimento. In: Congresso Brasileiro de Geologia de Engenharia, 8, 1996, Rio de Janeiro. Anais. Rio de Janeiro: ABGE, p. 369-380, 1996.

KÁLIX, T. M. F., Estudo de caracterização tecnológica com ênfase em alterabilidade dos tipos comerciais do "granito" Marrom Imperial, dissertação, UFPE, Recife, 2011. 114p.

MARANHÃO, R. J. L. Principais Depósitos Minerais do Brasil, Vol. 4. Departamento Nacional da Produção Mineral - DNPM, Brasília - DF, p. 437- 454, 1991.

MENDES, V.A., Estudo geoestrutural do maciço de granito vermelho frevo Sertânia, PE, dissertação, UFPE, Recife, 2008. 180p.

MENDES, V.A; PAIVA, I. P. Condicionamento Geológico das Ocorrências de Rochas Ornamentais das Folhas Garanhuns e Belém do São Francisco In: III Simpósio de Rochas Ornamentais do Nordeste, Recife, p. 99-112, 2002.

ROLIM FILHO, J.L. Caracterização de rochas ornamentais (Determinação de índices físicos). Relatório de resultados de testes geomecânicos. Área Fazendas Lagoa de Dentro e Barriguda, Alagoinha, PE. Relatório para a Associação Tecnológica do Estado de Pernambuco (ATEPE), 1996.

SOUZA, V. C., "Diagnóstico do setor de rochas ornamentais e de revestimento do estado de Pernambuco", dissertação, UFPE, Recife, 2008. 167p.

www.abirochas.com.br, acesso em 26/02/2013.

VARGAS, T; MOTOKI, A; NEVES, J.L.P., Rochas ornamentais do Brasil, seu modo de ocorrência geológica e utilidade como materiais nobres de construção. Disponível em: <http://akmotoki.tripod.com/2001/Itu2/Itu2_2.html> Acesso em: 19/06/2013. 